Canadian

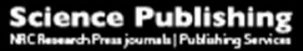

Botany

Botanique

\title{
Leaf herbivory induces resistance against florivores in Raphanus sativus
}

\begin{tabular}{|c|c|}
\hline Journal: & Botany \\
\hline Manuscript ID & cjb-2017-0153.R2 \\
\hline Manuscript Type: & Note \\
\hline Date Submitted by the Author: & $18-N o v-2017$ \\
\hline Complete List of Authors: & $\begin{array}{l}\text { McCall, Andrew; Denison University, Biology } \\
\text { Case, Samantha; North Carolina State University, Department of Plant and } \\
\text { Microbial Biology } \\
\text { Espy, Kelsy; Denison University, Biology } \\
\text { Adams, Grant; University of Southern Mississippi, School of Ocean Science } \\
\text { and Technology } \\
\text { Murphy, Stephen; Ohio State University, Department of Evolution, Ecology, } \\
\text { and Organismal Biology }\end{array}$ \\
\hline $\begin{array}{r}\text { Is the invited manuscript for } \\
\text { consideration in a Special } \\
\text { Issue? : }\end{array}$ & N/A \\
\hline Keyword: & $\begin{array}{l}\text { anthocyanins, floral herbivory, florivory, induced resistance, } \\
<\mathrm{i}></ \mathrm{i}>\text { Raphanus sativus }<\mathrm{i}></ \mathrm{i}>\end{array}$ \\
\hline
\end{tabular}


1 Leaf herbivory induces resistance against florivores in Raphanus sativus

Andrew C. McCall1*

Samantha Case $\mathrm{C}^{1,2}$

Kelsy Espy ${ }^{1}$

Grant Adams ${ }^{1,3}$

Stephen J. Murphy1,4

2. Department of Plant and Microbial Biology, North Carolina State University, Raleigh NC 27695 USA

3. Division of Coastal Sciences, School of Ocean Science and Technology, University of Southern Mississippi, Ocean Springs, MS 39564 USA 


\section{Abstract}

25 Florivory can have significant negative effects on plant fitness, driving selection for

26 resistance traits in flowers. In particular, herbivory to leaves may induce resistance

27 in flowers because herbivores on leaves often become florivores on flowers as plant

28 ontogeny proceeds. The literature on inducible resistance in floral tissues is limited,

29 so we used a series of experiments to determine if prior leaf damage by Spodoptera

30 exigua caterpillars affected florivore preference and performance on wild radish

31 (Raphanus sativus L.). We found that S. exigua larvae preferred petals from control

32 plants versus petals from plants exposed to prior leaf damage, and that larvae

33 gained more weight on petals from control plants, although this depended on the

34 presence of anthocyanins in the petals. Our results suggest that leaf damage can

35 induce changes in petals that reduce S. exigua larval fitness.

36 Key words: anthocyanins, floral herbivory, florivory, induced resistance, Raphanus

37 sativus

38 


\section{Introduction}

40 Many different types of herbivores may feed on a plant during its growth and

41 development. Some of these herbivores specialize on particular parts of the plant,

42 while others are more general in their preferences. For example, some herbivores

43 primarily feed on roots, some on shoots, and others on floral tissues. Florivores,

44 those animals feeding on floral tissue, are some of least studied among herbivores

45 (McCall and Irwin 2006). These organisms consume floral tissues before

46 maturation of the seed, and thus can have direct and indirect effects on overall plant

47 fitness.

49 Florivores may eat or damage the primary reproductive organs in a flower

50 (Krupnick and Weis 1999). This can result in nearly complete seed loss in some

51 plant populations (Washitani et al. 1996). Other types of damage may affect tissues

52 involved in pollinator signaling, like petals (McCall 2008). Damage to these tissues

53 can result in reduced reproduction through reduced pollinator service and/or seed

54 set (Karban and Strauss 1993; Lohman et al. 1996; Cardel and Koptur 2010; see

55 González-Browne et al. 2016 for a meta-analysis). Given the potential fitness costs

56 of florivory, plants may have evolved to limit the amount of damage caused by

57 florivores through physical and/or chemical resistance. One framework that can

58 explain the distribution of these traits is the Optimal Defense Theory (ODT) (McKey

59 1974; Rhoades 1979). ODT assumes that there is a substantial cost to producing

60 resistance traits, such that all tissues cannot be maximally protected at all times.

61 Given this tradeoff, ODT predicts that resistance should be higher in tissues that are 
62 more valuable, more likely to be attacked by herbivores, or are less costly to defend

63 (McKey 1974; Rhoades 1979).

64

65 Plant resistance may also vary depending on herbivore activity. Constitutive

66 resistance is active without an initial trigger, whereas induced resistance is only

67 activated after an initial bout of herbivore damage or some other trigger (Karban

68 and Baldwin 1997). Induced resistance is thought to be less costly than constitutive

69 resistance because it is not activated if initial damage does not occur. Thus, ODT

70 predicts that less valuable tissues will be protected with inducible resistance,

71 whereas more valuable tissues would be protected with constitutive resistance, all

72 other factors being equal (Karban and Nagasaka 2004). Induced resistance in

73 flowers is not without costs, though, as induction by leaf damage can reduce

74 pollinator attractiveness in Solanum peruvianum (Kessler et al. 2011). In another

75 example, natural leaf damage to Sinapis arvensis affected both pollinator preference

76 and the pollinator-plant community networks that included S. arvensis, possibly due

77 to changes in floral volatiles (Hoffmeister et al. 2016).

79 Flowers might be expected to have high levels of constitutive resistance because

80 they are directly involved in fitness and are usually highly apparent to visual

81 herbivores (Zangerl and Rutledge 1996; Strauss et al. 2004; McCall and Irwin 2006).

82 Researchers have found inducible responses in flowers. In particular, damage to

83 leaves can lead to increased resistance in flowers. This mechanism may be adaptive

84 if the same leaf herbivores also eat flowers, which has been reported in the 
85 literature (e.g. Agerbirk et al. 2010; Merwin and Parrella 2014; Abdalsamee and

86 Müller 2015). In some systems, a leaf herbivore first eats leaves and then moves up

87 a stem to feed on flowers or inflorescence tissue (Smallegange et al. 2007; Bandeili

88 and Müller 2010). Under these circumstances, a plant may be selected to defend its

89 reproductive tissues after initial damage to its leaves because leaf damage would be

90 a reliable predictor of floral damage. For example, leaf damage can increase floral

91 nicotine levels in Nicotiana attenuata (Euler and Baldwin 1996). McCall and Karban

92 (2006) showed that artificial leaf damage and methyl jasmonate were able to deter

93 florivory in N. attenuata. In Raphanus sativus, leaf damage increased total

94 glucosinolate concentrations in flowers (Strauss et al. 2004). Researchers have also

95 found inducible chemicals in floral nectar. Halpern et al. (2010) showed that leaf

96 damage can increase nicotine concentrations in Nicotiana quadrivalvis nectar and

97 Adler et al. (2006) showed that leaf damage increased alkaloid levels in Nicotiana

98 tabacum nectar.

100 Despite these gains, past studies focused solely on tissue chemistry, and no research

101 to date has addressed whether induced resistance in floral tissue has an actual effect

102 on florivore preference and performance. For selection to favor induced resistance

103 in flowers, there should be a negative effect of induction on florivores, especially if

104 the florivores are also leaf herbivores early in plant ontogeny. As of yet, there is no

105 work investigating if induced resistance, triggered by leaf damage, can negatively 106 affect florivore performance. 
108 Genetic variation within populations is also necessary for natural selection of

109 induced resistance in flowers. Researchers have found significant genetic variation

110 in induced resistance in leaves, although few have investigated how genetic

111 variation affects induced resistance in floral tissues. In a rare example, Strauss et al.

112 (2004) found that although different families differed in glucosinolate

113 concentrations in Raphanus sativus, the strength of induction across petals and

114 leaves did not depend on maternal family. Because of the paucity of studies on the

115 variation in floral induction strength within populations, we investigated whether

116 induced resistance differs within maternal families in a single population.

118 The above studies considered genetic variation within single populations, but the

119 strength of induction observed in one particular population may not be

120 generalizable to other populations. In fact, there is reason to expect induction to

121 vary across plant populations, especially if the type of herbivores and the severity of

122 their damage varies across those populations (Karban and Nagasaka 2004). To our

123 knowledge, no one has investigated whether different plant populations differ in

124 their strength of induced resistance in floral tissue or if induced resistance, in

125 general, affects florviore performance.

126

127 Using the model species Raphanus sativus, we consider several questions related to

128 the aforementioned gaps in our knowledge about induced resistance in flowers.

129 First, we ask whether prior damage to leaves affects florivore preference of petals.

130 Second, we ask if prior leaf damage affects florivore performance, as measured by 
131 weight, on petals among maternal families within a single population. Third, we ask

132 if the effects of leaf damage on florivore performance differ among several plant

133 populations and if petal anthocyanin presence affects induced resistance.

134

135

136

137 


\section{Methods}

\section{Plant system}

140 Raphanus sativus L. is an annual plant produced from crosses between $R$.

141 raphinistrum and agronomic $R$. sativus cultivars (Hegde et al. 2006). Its seeds

142 germinate during the first part of the wet season in California's Mediterranean

143 climate (October-December), with plants flowering between March and July. Floral

144 color phenotype (bronze, pink, white, and yellow) is controlled by two

145 independently segregating loci (Panestsos 1964; Irwin et al. 2003). Leaf herbivores

146 include Plutella xylostella (Plutellidae) and Platyprepia virginalis (Erebidae), both of

147 which also can feed on flowers. On a single plant, Pl. virginalis and P. xylostella

148 individuals can be both leaf herbivores and florivores (A. McCall, personal

149 observation).

\section{Florivore choice and performance procedures}

151 We used the same general procedure to test florivore preference and performance

152 for the three experiments described below. We attempted to induce resistance

153 responses in $R$. sativus flowers by damaging the leaves of experimental plants with

154 Spodoptera exigua larvae, a generalist herbivore often used for bioassays. Half of the

155 plants were randomly chosen to receive herbivore damage by caging a neonate $S$.

156 exigua larva on the third true leaf. Control plants received a cage without any

157 larvae. We allowed the larvae on the experimental plants to feed until half of the

158 leaf area was consumed. Thus, every damaged plant received the same relative

159 amount of damage. We then removed all cages from control and experimental plants

160 and allowed the plants to grow until they flowered about 2 weeks later. Very little 
161 work on the duration of induction in Raphanus has been conducted, but Agrawal

162 (1999) showed that induction of resistance in leaves may last 6 weeks in $R$.

\section{3 raphinistrum.}

164

165 For the preference test, a single petal from a randomly-chosen control and

166 experimental plant of the same color morph was selected and placed in a $120 \mathrm{~mm}$

167 Petri dish, along with a moist ball of tissue paper to ensure that the petals would

168 remain fresh for consumption. For the performance tests, we selected two petals

169 from the newest flower on a plant and placed them in the arena with a moist tissue

170 paper ball and a neonate larva. Petals and tissue paper balls were replaced every

171 two days and petals always came from the same plant for each arena. The only

172 exception to this procedure was if the larvae ate all of the available petal tissue

173 before 2 days. If this happened, we added 2 more petals when the food supply was

174 exhausted. During the replacement of tissue, we weighed the petals to ensure that

175 constant weights were maintained among and within individual arenas. If weights

176 were not within $0.005 \mathrm{~g}$ of each other on successive days of the tests, we selected

177 new petals until the desired mass was achieved. We allowed the larvae to feed for

$17824 \mathrm{~h}$ for the preference test and for 10 days for the performance tests.

180 Preference

181 Forty R. sativus plants from five dams in the Jepson Prairie population (Table 1)

182 were grown in a greenhouse in September of 2008. After growing the experimental

183 and control plants as described above, we set up feeding trials where each larva 
184 could feed on petals obtained from damaged and undamaged plants. We allowed the

185 larvae to feed for $24 \mathrm{~h}$, after which we scored which flower disk had the most

186 damage. One larva escaped and we were unable to determine which disk had the

187 most damage in one arena, leaving us with 18 total replicates. We tested preference

188 using a Chi-square goodness-of-fit test.

189

\section{Performance: single population}

191 We also wanted to know if induction of resistance in petals or anther tissue could

192 affect $S$. exigua performance, measured as total weight gain. We employed a

193 bioassay method using S. exigua and plants from a population at Jepson Prairie,

194 California (Lat.: 38.303; Long.: $121.824^{\circ}$ ). On May 15, 2009, seeds from this

195 population were collected by placing a $20 \mathrm{~m}$ linear transect along the side of the road

196 where the bulk of the population was located. Silique-bearing plants at every $2 \mathrm{~m}$

197 were selected for collection, although there were only eight total plants that set fruit

198 in that year. Approximately 30 siliques from each maternal plant were haphazardly

199 collected and placed in paper bags at room temperature until germination for the

200 experiment. On November 10, 2009, five seeds from five different siliques per

201 maternal plant were planted in potting soil. Plants were grown under a 16h day: 8h

202 night regime in a pest-free greenhouse until the third true leaf was fully expanded

203 on each plant, when we applied the initial damage treatment. As the plants

204 flowered we also noted whether they expressed anthocyanins in their petals

205 (bronze and purple) or if they did not (white and yellow). 
207 We tested the performance of neonate S. exigua larvae using the methods described 208 above, feeding larvae petals from control or treatment plants. Initially we planted 20970 plants, with 36 plants randomly assigned to the control treatment and 34 plants

210 randomly assigned to the induction treatment. During the course of the feeding

211 trials 10 larvae died, resulting in 60 total replicates. There was no association of

212 larval death with a particular treatment (Chi-square $=1.611, P=0.20)$. Maternal

213 family 1 had 14 replicates, family 2 had 16 replicates, family 3 had 11 replicates, and

214 family 4 had 19 replicates. Fifty larvae were reared on pink-flowering plants and

215 ten were reared on white-flowering plants.

216

217 The data exhibited homogeneity of variances and were normally distributed, so we

218 performed a mixed-model ANOVA with the dependent variable of larval weight and

219 the independent variables of planting block, maternal family, damage treatment, and

220 the interaction between maternal family and damage treatment. We considered

221 planting block as a random effect and maternal family a fixed effect because we

222 sampled a large proportion (approximately 50\%) of this population.

\section{Performance: multiple populations}

225 In order to test whether the effects of prior leaf damage are dependent on the

226 population being tested and to see if the presence of anthocyanins affected the

227 results, we conducted an experiment where we manipulated leaf damage on plants

228 from several populations of $R$. sativus. These populations were a subset of those

229 used in an earlier experiment that investigated whether variance in leaf damage was 
230 related to inducibility of defense in leaves (Karban and Nagasaka 2004). Those

231 populations in Karban and Nagasaka (2004) were originally chosen because they

232 spanned a climatic gradient from wet areas to dry areas in Northern California. 233

234 We planted 10 seeds from each of 12 R. sativus populations in a pollinator-free

235 greenhouse. Nine seeds failed to germinate, leaving us with 111 plants for the

236 experiment. We again produced experimental and control plants using the general

237 procedure outlined above. During the course of the experiment 34 larvae died, so

238 we were left with 77 living larvae at the end of 10 days. There was no difference in

239 the proportion of larvae that died between the damage treatments $\left(\mathrm{X}^{2}=1.54,1 \mathrm{df}, P\right.$

$240=0.22$ ). We then reduced the data set further by excluding those populations

241 (CHER, DIXO, NAPA, PLIN, STRW, see Table 1) that did not have at least two

242 replicates of each treatment or anthocyanin morph. This left us with 58 total plants

243 in seven populations for the final analysis (Table 1). There were 34 control plants

244 and 24 experimental plants and 28 with anthocyanins present in their flowers

245 versus 30 plants with anthocyanins absent from their flowers.

247 The data exhibited homogeneity of variances and residuals were normally-

248 distributed, so we performed a mixed-model ANOVA to test if planting block,

249 population, anthocyanin presence in petals, population by treatment or population

250 by anthocyanin had significant effects on larval weight gain after 10 days of feeding.

251 We considered the population, population by treatment, and planting block as

252 random effects. We determined the significance of random factors by examining the 
$25395 \% \mathrm{CI}$; if these intervals included zero, then the random effect was not considered

254 significant at the $\alpha=0.05$ level. We included anthocyanin presence in the petals

$255(\mathrm{~A}+/ \mathrm{A}-)$ and the interaction between anthocyanin presence and the treatment effect

256 because different color morphs are known to induce different levels of

257 glucosinolates (Strauss et al. 2004).

258

259 All analyses were performed using JMP Pro v.12 (SAS Institute, Cary, NC USA)

260

261 


\section{Results}

\section{Preference}

264 S. exigua larvae preferred petals from undamaged plants in 15 out of $18(83.3 \%)$

265 trials. This number was significantly different from the numbers expected from the

266 null hypothesis of no preference between the treatments $\left(X^{2}=8.0,1 \mathrm{df}, P=0.005\right)$.

\section{Performance: single population}

269 For insects reared on petals, there was a significant effect of planting block

270 (variance component $=1.01 \mathrm{e}-8, P<0.05$ ) and no significant effect of the damage

271 treatment $\left(F_{1,51}=2.96, P=0.09\right)$, or maternal family $\left(F_{3,51}=0.38, P=0.77\right)$ on larval

272 weight after ten days. There was a strong trend for an interaction between damage

273 treatment and maternal family $\left(F_{3,51}=2.76, P=0.051\right)$. On examining the simple

274 effects of damage treatment within each maternal family, there were no significant

275 effects of damage in families $1\left(F_{1,51}=2.42, P=0.13\right), 2\left(F_{1,51}=0.77, P=0.38\right)$, or 4

$276\left(F_{1,51}=2.38, P=0.12\right)$, but larvae from control treatments weighed $79 \%$ more than

277 larvae from damage treatments in family $3\left(F_{1,51}=4.69, P=0.03\right.$, see Figure 1$)$.

\section{Performance: multiple populations}

280 Planting block in the greenhouse had a significant effect on larval weight (variance

281 component $=1.51 \mathrm{e}-8, P<0.05)$. There was no significant effect of population

282 (variance component $=8.19 \mathrm{e}-9, P>0.05$ ), and no significant population by treatment

283 effect (variance component $=-1.00 \mathrm{e}-8, P>0.05$ ). For fixed effects, there was a

284 significant effect of the leaf damage treatment, such that larvae on damaged plants 
285 weighed $18 \%$ less than larvae on undamaged plants $\left(F_{1,9.01}=6.42, P=0.03\right)$ and no 286 significant effect of petal anthocyanins on larval weight $\left(F_{1,37.18}=0.84, P=0.36\right)$. 287 There was a significant leaf damage by petal anthocyanin interaction $\left(F_{1,13.3}=5.59, P\right.$ $288=0.03$ ). Examining the simple effects within anthocyanin-free morphs, we found 289 that larval weights were significant lower on petals from damaged plants than on 290 petals from undamaged plants $\left(F_{1,19.5}=9.66, P=0.006\right)$. In contrast, there were no 291 significant effects of leaf damage on larval weight in morphs containing 292 anthocyanins in their petals $\left(F_{1,5.43}=0.012, P=0.92\right.$, see Figure 2$)$. 293 294 295 296 297 


\section{Discussion}

299 If induced resistance occurs in petals, we might expect that florivores to choose

300 petals from undamaged versus damaged plants. We found evidence that leaf damage

301 can alter the preference for petals. Specifically, florivores preferred petals from

302 control plants versus petals from plants with prior leaf damage. This finding is

303 consistent with the idea that insects can initially reject petals due to induced

304 secondary compounds in the flowers, physical changes in petal structure, or changes

305 in the nutritional composition of the flowers. To our knowledge, this is the first

306 evidence showing that florivores show a preference for petals from undamaged

307 versus damaged plants. Likewise, larvae reared on petals from damaged plants

308 gained significantly less weight than those larvae reared on petals from control

309 plants. We observed this both within a single population and across multiple

310 populations, although this depended on the anthocyanin content in the latter case.

311 These results suggest that either signals from damaged leaves or defensive

312 chemicals themselves are able to travel to flowers after initial herbivore damage

313 and can have negative effects on florivore health.

315 Other researchers have found that prior damage to plant tissue can also affect floral

316 visitors, although few have documented a negative fitness effect on florivores. For

317 example, McCall and Karban (2006) found that both insect damage and application

318 of methyl jasmonate on leaves decreased florivore damage in Nicotiana attenuata.

319 In Nemophila menziesii, McCall (2006) showed that initial damage to flowers could

320 reduce florivory in later flowers, but they did not examine florivore performance. 
321 Our current work suggests that plants can employ less costly inducible resistance in

322 petals. Our results could be explained by ODT if flowers, and petals in particular, are

323 relatively cheap to produce or if more constitutive resistance may negatively affect

324 pollination (McCall and Irwin 2006). Raphanus sativus plants often make hundreds

325 of flowers (A. M., personal observation) so that the sheer number of flowers

326 available for reproduction may mitigate the cost of losing petal tissue when

327 florivore pressure is relatively low. This, in turn, might preclude the selection for

328 costly constitutive chemical defenses in the flowers. Another reason that R. sativus

329 might be selected to induce resistance in flowers is because induction is adaptive

330 with respect to florivore behavior. For example, if florivores start their lives on

331 basal leaves, they can move acropetally to the top of the plant, where inflorescences

332 will be at risk for damage. This type of movement has been observed in larvae

333 feeding on other Brassicaceae (Smallegange et al. 2007; Bandeili and Müller 2010),

334 so it is possible that $R$. sativus may induced resistance against similar florivores.

336 We also found evidence that induction of resistance varies with maternal family in

337 the Jepson population. This may not be surprising, as Agrawal et al. (2002) found

338 significant additive genetic variation in the strength of induction in Raphanus

339 raphanistrum leaves. It would be interesting to investigate whether those

340 genotypes that display high levels of induced resistance in leaves also have high

341 levels of induction in flowers. 
343 Interestingly, we found no evidence that induced resistance in flowers varied

344 among populations of $R$. sativus, even though the type and intensity of herbivory did

345 vary across the populations (see Table 1). This is in contrast to Karban and

346 Nagasaka's (2004) findings that populations of $R$. sativus along a climatic gradient in

347 Northern California exhibited significant variation in induction of resistance in

348 leaves. Our results may differ from this study for at least two reasons. First, our

349 sample sizes per population were much lower, with an average of 8 plants per

350 population, so it is possible that we did not have enough statistical power to detect

351 differences in induction. Second, it is possible that the variation in induced

352 responses in flowers does not necessarily reflect the amount of variation in

353 induction for leaves across these populations. This may be true in $R$. sativus, where

354 researchers found that floral glucosinolates were not as inducible as leaf

355 glucosinolates within a population (Strauss et al. 2004).

356

357 We also found that induction of resistance in petals depended on the presence of

358 anthocyanins in petals in the multiple population experiment. In particular, induced

359 resistance was only found in anthocyanin-free petals. This could be due to

360 pleiotropic action of genes involved in producing glucosinolates and the precursors

361 to anthocyanins (Hemm et al 2003). Strauss et al. (2004) found that white and pink

362 flowers had similar constitutive concentrations of gluosinolates, but that

363 glucosinolates were induced at higher levels in pink R. sativus flowers than in the

364 white morphs. This is in contrast to our findings, and could be explained because

365 we used different populations of $R$. sativus than Strauss et al. (2004) or that our 
366 methods of induction were not identical. Alternatively, glucosinolate induction in

367 pink morphs as shown by Strauss et al. (2004) may not necessarily translate into

368 reduced performance of florivores relative to the other color morphs.

370 Although we showed that leaf damage has negative effects on florivores, we cannot 371 necessarily conclude that induction is an adaptation to reduced flower damage in $R$. 372 sativus. Alternatively, damage to leaves may increase levels of defensive chemicals, 373 reduce nutrient concentration or availability, or affect some other physical attribute 374 in the entire plant, with effects on florivores being a nonadaptive side effect of the 375 leaf damage. This hypothesis would mirror Adler's (2000) nonadaptive hypothesis

376 regarding correlated concentrations of resistance compounds in leaves and nectar.

377 Manson et al. (2012) found that pooled concentrations of cardenolides across 12

378 Asclepias species were positively correlated in nectar and leaves, possibly giving 379 support to the nonadaptive hypothesis. Alternatively, the authors also found that

380 the qualitative profiles of cardenolides were significantly different among nectar 381 and leaf samples.

\section{Conclusions}

384 We show that S. exigua larvae both prefer petals from control plants and perform 385 better on control plant petals than on damaged plant petals. This effect is dependent

386 on maternal family identity in at least one population, and across multiple

387 populations the effect was only seen in plants without anthocyanins in their petals.

388 These results suggest that plants may protect themselves from leaf and floral 
389 damage through induction of resistance stimulated by relatively small levels of

390 initial leaf damage. Whether or not this effect can increase fitness of $R$. sativus under

391 field conditions remains an open, and important, question.

\section{Acknowledgements}

397 We would like to thank the Denison Department of Biology and the Anderson

398 Endowment for support of undergraduate summer research activities. Dr. Judie

399 Bronstein's lab at the University of Arizona provided a welcoming environment in

400 which to write this manuscript. We also acknowledge Mr. Whitney Stocker and Dr.

401 Warren Hauk for their help in the greenhouse portion of this work. 


\section{References}

403

404 Abdalsamee, M.K., and Müller, C. 2015. Uncovering different parameters influencing

405 florivory in a specialist herbivore. Ecol. Entomol. 40: 258-268.

406 doi:10.1111/een.12182.

407 Adler, L. 2000. The ecological significance of toxic nectar. Oikos, 91(3): 409-420.

408 doi:10.1034/j.1600-0706.2000.910301.x/pdf.

409 Adler, L.S., Wink, M., Distl, M., and Lentz, A.J. 2006. Leaf herbivory and nutrients

410 increase nectar alkaloids. Ecol. Lett. 9(8): 960-967. doi:10.1111/j.1461-

$411 \quad 0248.2006 .00944 . x$.

412 Agerbirk, N., Chew, F.S., Olesen, C.E., and K. Jørgensen. 2010. Leaf and floral parts

413 feeding by orange tip butterfly larvae depends on larval position but not

414 glucosinolate profile or nitrogen level. J. Chem. Ecol. 36(12): 1335-1345.

415 doi:10.1007/s10886-010-9880-5.

416 Agrawal, A.A. 1999. Induced responses to herbivory in wild radish: effects on

417 several herbivores and plant fitness. Ecology, 80(5): 1713-1723. doi:10.1890/0012-

418 9658(1999)080[1713:IRTHIW]2.0.CO;2

419 Agrawal, A.A., Conner, J.K., Johnson, M.T., and Wallsgrove, R. 2002. Ecological

420 genetics of an induced plant defense against herbivores: additive genetic variance

421 and costs of phenotypic plasticity. Evolution, 56 (11): 2206-2213.

422 doi:10.1111/j.0014-3820.2002.tb00145.x. 
423 Bandieli, B., and Müller, C. 2010. Florivory versus folivory - adaptiveness of flower

424 feeding. Naturwissenschaften, 97(1): 79-88. doi:10.1007/s00114-009-0615-9.

425 Cardel, Y.J., and Koptur, S. 2010. Effects of florivory on the pollination of flowers: an

426 experimental field study with a perennial plant. Int. J. Plant Sci. 171(3): 283-292.

427 doi:10.1086/650154.

428 Euler, M., and Baldwin, I.T. 1996. The chemistry of defense and apparency in the

429 corollas of Nicotiana attenuata. Oecologia, 107(1): 102-112.

430 doi:10.1007/BF00582240.

431 González-Browne, C., Murúa, M., Navarro, L., and Medel, R. 2016. Does plant origin

432 influence the fitness impact of flower damage? A meta-analysis. PLoS ONE, 11(1):

433 e0146437. doi:10.1371/journal.pone.0146437.

434 Halpern, S.L., Adler, L.S., and Wink, M. 2010. Leaf herbivory and drought stress affect

435 floral attractive and defensive traits in Nicotiana quadrivalvis. Oecologia, 163(4):

436 961-971. doi:10.1007/s00442-010-1651-z.

437 Hegde, S.G., Nason, J.D., Clegg, J.M., and Ellstrand, N.C. 2006. The evolution of

438 California's wild radish has resulted in the extinction of its progenitors. Evolution,

439 60(6): 1187-1197. doi:10.1111/j.0014-3820.2006.tb01197.x.

440 Hemm, M.R., Ruegger, M.O., and Chapple, C. 2003. The Arabidopsis ref2 mutant is

441 defective in the gene encoding CYP83A1and shows both phenylpropanoid and

442 glucosinolate phenotypes. Plant Cell, 15 (1): 179-194. Stable 
443 URL:https://www.ncbi.nlm.nih.gov/pmc/articles/PMC143490/

444 Hoffmeister, M., Wittköpper, N., and Junker, R. 2015. Herbivore-induced changes in

445 flower scent and morphology affect the structure of flower-visitor networks but not plant

446 reproduction. Oikos, 125(9): 1241-1249. doi:10.1111/oik.02988.

447

448 Irwin, R.E., Strauss, S.Y., Storz, S., Emerson, A., and Guibert, G. 2003. The role of

449 herbivores in the maintenance of a flower color polymorphism in wild radish.

450 Ecology, 84(7): 1733-1743. doi:10.1890/0012-

$4519658(2003) 084[1733:$ TROHIT]2.0.CO;2.

452 Karban, R., and Baldwin, I.T. 1997 Induced responses to herbivory. University of

453 Chicago Press, Chicago

454 Karban, R., and Nagasaka, K. 2004. Are defenses of wild radish populations well

455 matched with variability and predictability of herbivory? Evol. Ecol. 18(3): 283-301.

456 doi:10.1023/B:EVEC.0000035063.70344.03.

457 Karban, R., and Strauss S.Y. 1993. Effects of herbivores on growth and reproduction

458 of their perennial host, Erigeron glaucus. Ecology, 74(1): 39-46.

459 doi:10.2307/1939499.

460 Kessler, A., Halitschke, R., and Poveda, K. 2011. Herbivory-mediated pollinator

461 limitation: negative impacts of induced volatiles on plant-pollinator interactions.

462 Ecology, 92(9): 1769-80. doi:10.1890/10-1945.1 
463 Krupnick, G.A., and Weis, A.E. 1999. The effect of floral herbivory on male and

464 female reproductive success in Isomeris arborea. Ecology, 80(1): 135-1149.

465 doi:10.1890/0012-9658(1999)080[0135:TEOFHO]2.0.CO;2.

466 Lohman, D.J., Zangerl, A.R., and Berenbaum, M.R. 1996. Impact of floral herbivory by

467 parsnip webworm (Oecophoridae: Depressaria pastinacella Duponchel) on

468 pollination and fitness of wild parsnip (Apiaceae: Pastinaca sativa L.). Am. Midl. Nat.

469 136(2): 407-412. doi:10.2307/2426744.

470 Manson, J.S., Rasmann, S., Halitschke, R., Thomson, J.D., and Agrawal, A.A. 2012.

471 Cardenolides in nectar may be more than a consequence of allocation to other plant

472 parts: a phylogenetic study of Asclepias. Funct. Ecol. 26(5): 1100-1110.

473 doi:10.1111/j.1365-2435.2012.02039.x.

474 McCall, A.C. 2006. Induced defense in Nemophila menziesii flowers. Oikos, 112(3):

475 660-666. doi:10.1111/j.0030-1299.2006.13981.x.

476 McCall, A.C. 2008. Florivory affects pollinator visitation and female fitness in

477 Nemophila menziesii. Oecologia, 155(4): 729-737. doi:10.1007/s00442-007-0934-5. 478

479 McCall, A.C., and Fordyce, J.A. 2010. Can optimal defense theory be used to predict 480 the distribution of plant chemical defenses? J. Ecol. 98(5): 985-992. doi: $481 \quad 10.1111 / \mathrm{j} .1365-2745.2010 .01693 . x$.

482 McCall, A.C., and Irwin, R.E. 2006. Florivory: The intersection of pollination and 483 herbivory. Ecol. Lett. 9(12): 1351-1365. doi:10.1111/j.1461-0248.2006.00975.x. 
484 McCall, A.C., and Karban, R. 2006. Induced defense in Nicotiana attenuata

485 (Solanaceae) fruit and flowers. Oecologia, 146(4): 566-571. doi:10.1007/s00442486 005-0284-0.

487 McCall, A.C., Murphy, S.J., Venner, C., and Brown, M. 2013. Florivores prefer white 488 versus pink petal color morphs in wild radish, Raphanus sativus. Oecologia, 172(1): 489 189-195. doi:10.1007/s00442-012-2480-z.

490 McKey, D. 1974. Adaptive patterns in alkaloid physiology. Am. Nat. 108(961): 305491 320. doi:10.1086/282909.

492 Merwin, A.C., Parrella, M.P. 2014. Preference induction and the benefits of floral 493 resources for a facultative florivore. Ecol. Entomol. 39(4): :405-411.

494 doi:10.1111/een.1211.

495 Panestsos, C.P. 1964. Sources of Variation in Wild Populations of Raphanus 496 (Cruciferae). PhD thesis, University of California, Berkeley?

497 Rhoades, D.F. 1979. Evolution of plant chemical defense against herbivores. In 498 Herbivores: their interaction with secondary plant metabolites. Edited by G.A. 499 Rosenthal and D.H. Janzen. Academic Press, New York, N.Y. pp. 1-55.

500 Smallegange, R.C., van Loon, J.J.A., Blatt, S.E., Harvey, J.A., Agerbirk, N., and Dicke, M. 501 2007. Flower vs. leaf feeding by Pieris brassicae: glucosinolate-rich flower tissues 502 are preferred and sustain higher growth rate. J. Chem. Ecol. 33(10): 1831-1844. 503 doi:10.1007/s10886-007-9350-x. 
504 Strauss, S.Y., Irwin, R.E., and Lambrix, V. 2004. Optimal defense theory and flower

505 petal colour predict variation in the secondary chemistry of wild radish. J. Ecol.

506 92(1): 132-141. doi:10.1111/j.1365-2745.2004.00843.x.

507 Washitani, I., Okayama, Y., Sato, K., Takahashi, H., and Ohgushi, T. 1996. Spatial

508 variation in female fertility related to interactions with flower consumers and

509 pathogens in a forest metapopulation of Primula sieboldii. Res. Popul. Ecol. 38(2)

510 :249-256. doi:10.1007/BF02515734.

511 Zangerl, A.R., and Rutledge, C.E. 1996. The probability of attack and patterns of

512 constitutive and induced defense: a test of optimal defense theory. Am. Nat. 147(4):

513 599-608. Stable URL: http://www.jstor.org/stable/2463237

514 
515 Table 1. Locations of populations of Raphanus sativus where seed was originally 516 collected. Bolded populations indicate those populations that were used in the 517 multiple populations experiment. The remaining populations did not have enough 518 variation in petal anthocyanins to include in the final analysis.

519

\begin{tabular}{|l|l|l|}
\hline Population & Latitude & Longitude \\
\hline CHER & 38.336 & 121.022 \\
\hline CONS & $\mathbf{3 8 . 2 5 7 5}$ & $\mathbf{1 2 1 . 4 4 1}$ \\
\hline DIXO & 38.361 & 121.824 \\
\hline HOOD & $\mathbf{3 8 . 3 6 4}$ & $\mathbf{1 2 1 . 5 1 0}$ \\
\hline NAPA & 38.221 & 122.238 \\
\hline PEDR & $\mathbf{3 8 . 5 1 1}$ & $\mathbf{1 2 1 . 8 0 4}$ \\
\hline PLIN & 38.584 & 121.732 \\
\hline SNOD & $\mathbf{3 8 . 2 7 7 2}$ & $\mathbf{1 2 1 . 5 0 0 8}$ \\
\hline SONO & $\mathbf{3 8 . 2 3 5 6}$ & $\mathbf{1 2 2 . 5 2 9 2}$ \\
\hline STON & $\mathbf{3 8 . 4 0 8 3}$ & $\mathbf{1 2 1 . 4 8 9 2}$ \\
\hline STRW & 38.563 & 121.800 \\
\hline YOLO & $\mathbf{3 8 . 5 5 7}$ & $\mathbf{1 2 1 . 6 7 2}$ \\
\hline & & \\
\hline
\end{tabular}




\section{Figure Legends}

524

525 Fig. 1 The effects of maternal family and leaf damage treatment on the weights of

526 Spodoptera exigua larvae after 10 days of feeding on petals. Black bars represent

527 larval weights from control plants and grey bars represent larval weights from the

528 leaf damage treatment. Bars represent means \pm 1 SE.

529

530 Fig. 2 The effect of leaf damage and petal anthocyanin content on Spodoptera exigua

531 weight after 10 days of feeding on petals. Plants were grown from seven different

532 populations in Northern California (see Table 1). Black bars represent larval

533 weights from control plants and grey bars represent larval weights from the leaf

534 damage treatment. Bars represent means \pm 1 SE.

535

536 
$537 \quad$ Fig. 1

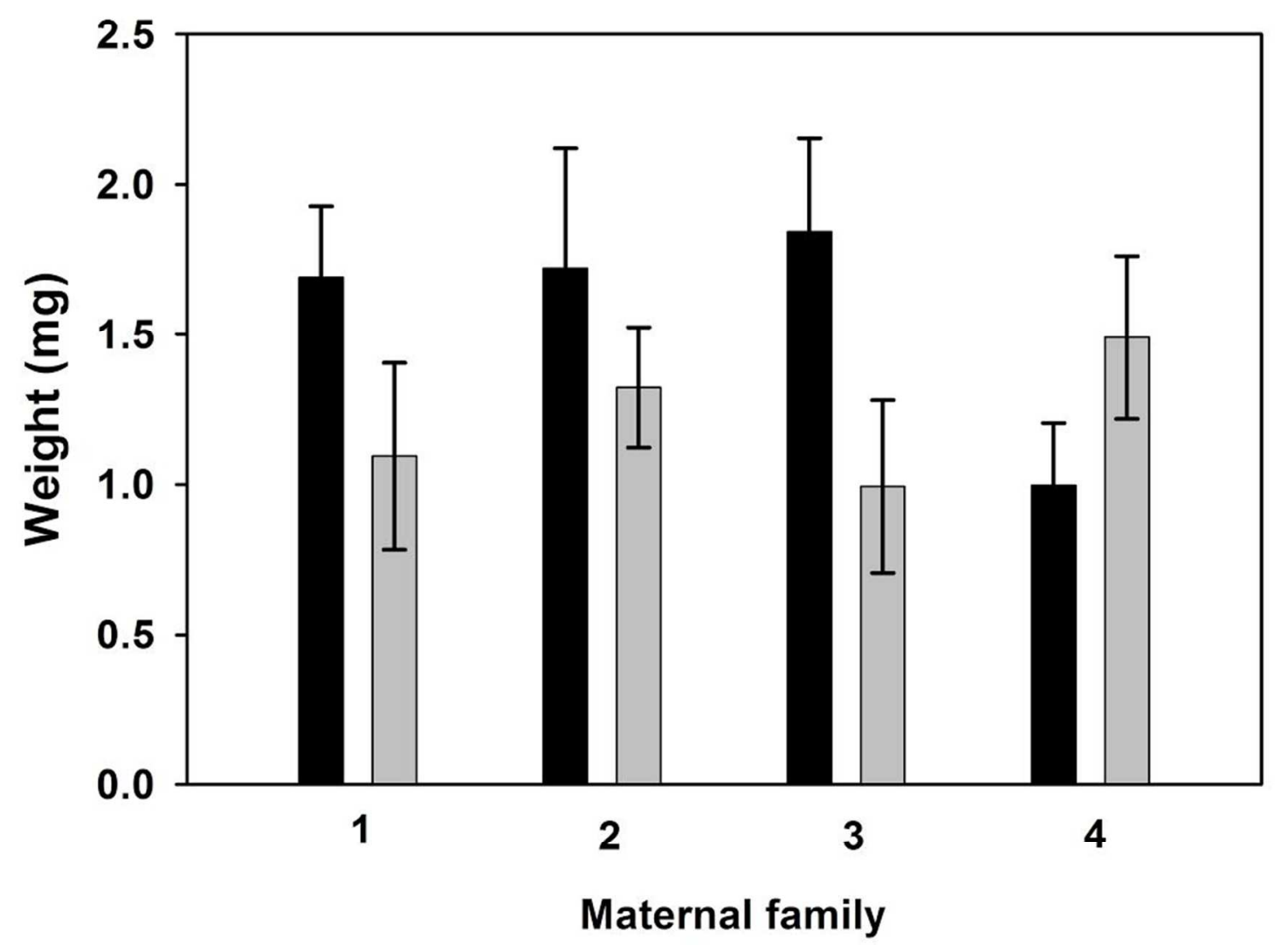

538

539 
$540 \quad$ Fig. 2

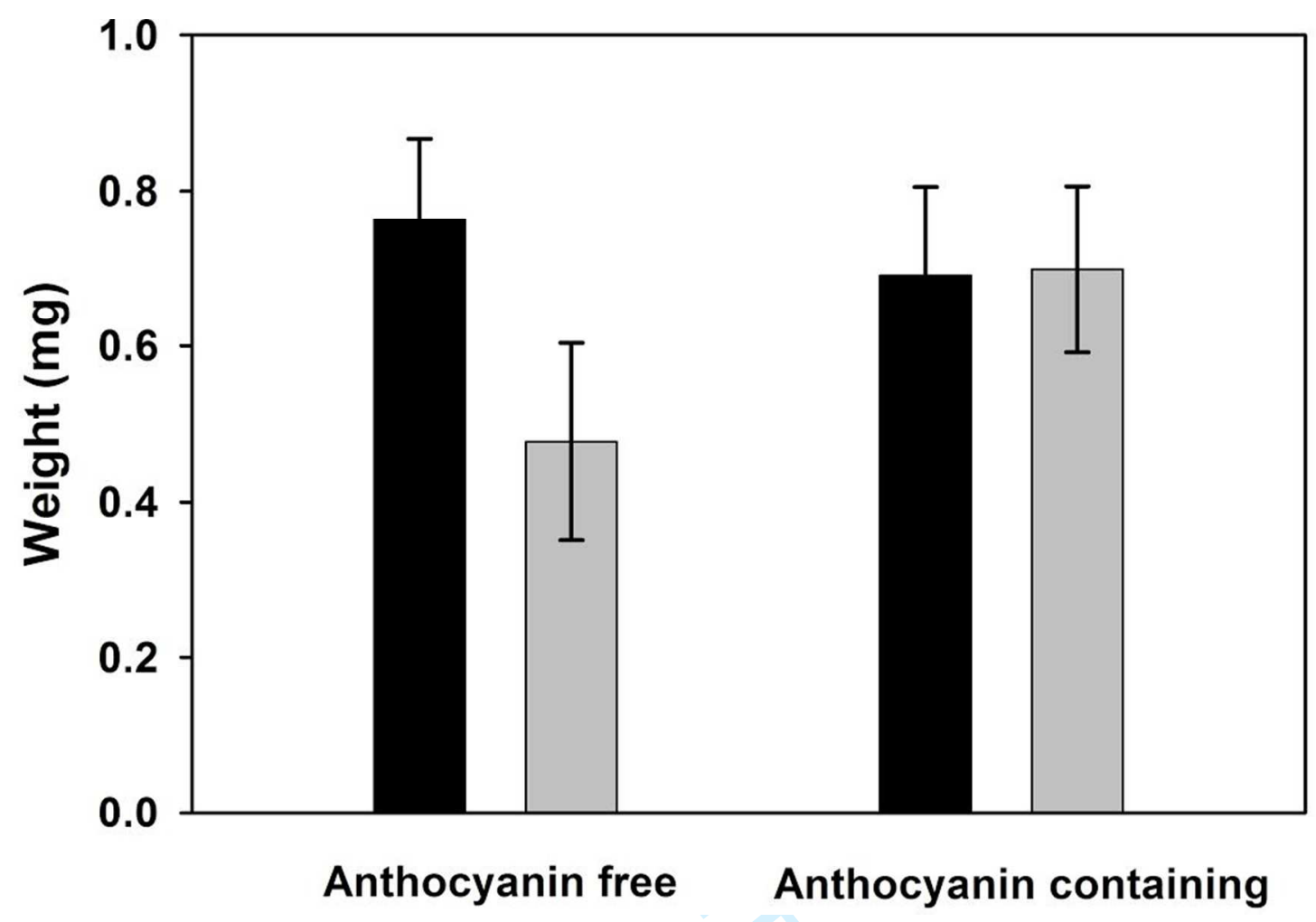

541

542 